\title{
NODULAÇÃO E MICORRIZAÇÃO EM Anadenanthera peregrina VAR. falcata EM SOLO DE CERRADO AUTOCLAVADO E NÃO AUTOCLAVADO(1)
}

\author{
E. GROSS ${ }^{(2)}$, L. CORDEIRO(3) \& F. H. CAETANO ${ }^{(4)}$
}

\begin{abstract}
RESUMO
Anadenanthera peregri na var. falcata (angico-do-cerrado), uma leguminosa arbórea, forma associações simbióticas com bactérias fixadoras de nitrogênio (rizóbios) e com fungos micorrízicos arbusculares. Com o objetivo de avaliar a eficiência da inoculação de fungos micorrízi cos e rizóbios no crescimento inicial de plantas de angico-do-cerrado, crescidas em solo autoclavado e em solo não autoclavado com e sem inoculação, foi desenvolvido um experimento em casa de vegetação, utilizando raízes micorrizadas de milho e uma mistura de isolados de rizóbios como inoculantes. 0 crescimento das plantas foi influenciado positivamente pela concomitante inoculação do fungo micorrízico e do rizóbio, tendo as plantas desse tratamento apresentado biomassa cerca de $60 \%$ maior do que o controle no décimo mês. A inoculação de apenas um dos microssimbiontes, entretanto, não provocou diferença na produção de biomassa das plantas. A percentagem de colonização micorrízica foi significativamente mais alta e o número de nódulos maior nas raízes das plantas crescidas no solo não autoclavado, ocasi onados pela população de fungos e rizóbios nativos. Nesse tratamento, houve pequeno acúmulo de matéria no xilopódio, provavelmente em virtude do dreno fotossintético por parte dos microssimbiontes, e a concentração de $P$ na parte aérea e xilopódio dessas plantas foi cerca de 1,2 e 8 vezes maior, respectivamente, por causa da colonização micorrízica.
\end{abstract}

Termos de indexação: angico-do-cerrado, rizóbio, fungos micorrízicos arbusculares.

\footnotetext{
(1) Parte da Tese de Doutorado do primeiro autor, apresentada ao Departamento de Botânica da Universidade Estadual Paulista UNESP. Financiado pela FAPESP, processo no 98/09517-4. Recebido para publicação em agosto de 2002 e aprovado em novembro de 2003.

(2) Professor do Departamento de Biologia, Universidade Estadual de Feira de Santana - UEFS. Caixa Postal 252-294, CEP 44031460 Feira de Santana (BA). E-mail:edugross@rc.unesp.br

(3) Professora do Departamento de Botânica, Universidade Estadual Paulista - UNESP. Campus de Rio Claro. Caixa Postal 199, CEP 13506-900 Rio Claro (SP). E-mail: lazarac@rc.unesp.br

(4) Professor do Departamento de Biologia, UNESP. E-mail: fcaetano@rc.unesp.br
} 
SUMMARY: NODULATION AND MYCORRHIZAL INFECTION IN Anadenanthera peregrina VAR. falcata ON AUTOCLAVED AND NON-AUTOCLAVED CERRADO SOI L

\begin{abstract}
Theleguminous treeAnadenanthera peregrina var. fal cata (angi co-do-cerrado) forms symbiotic associati ons with nitrogen fixing bacteria (rhizobia) and arbuscular mycorrhizal fungi. Theaim of this study was theevaluation of theinfluence of rhizobial and arbuscular mycorrhizal inoculation on the initial growth of angico-do-cerrado plants, in autoclaved and non-autoclaved soil with and without inoculations. Theexperiment was carried out in a greenhouseusing mycorrhized roots of maizeand a mixture of rhizobial isol ates as inocula. Plant growth was positively affected by dual inoculation of mycorrhizal fungus and rhizobia: plants of this treatment produced $60 \%$ morebi omass than in the control in the 10th month. I noculation of only onemicrosymbi ont, however, did not promotedifferencein plant growth. Mycorrhizal formation was significantly more extensiveand the number of nodules higher in plants of non-autoclaved soil, caused by native soil borne fungi and rhizobia. In this treatment mass accumulation was lowest in the xylopodium, probably because of the photosynthetic drain caused by microsymbionts, and $\mathrm{P}$ concentrations in shoot and xylopodium were about 1.2 and 8 times higher in these plants, respectively, due to the mycorrhizal colonization.
\end{abstract}

Index terms: angi co-do-cerrado, rhizobia, arbuscular mycorrhizal fungi .

\section{INTRODUÇÃO}

Plantas da família Leguminosae podem formar associações simbióticas tanto com bactérias fixadoras de nitrogênio, chamadas de rizóbio, como com fungos micorrízicos arbusculares. N essa associação mutualista tripartida, os fungos micorrízicos podem aumentar a solubilização e a absorção de fósforo do solo através do micéli o extra-radicular, transl ocando esse el emento para o vegetal. Por sua vez, o rizóbio, localizado em células especiais do nódulo, fixa o nitrogênio atmosférico disponi bilizando-o sob forma de amônia para a planta, a qual, em contrapartida, fornece carboidratos para ambos os mi crossimbiontes (Alen \& Alen, 1981; Harley \& Smith, 1983).

O angico-do-cerrado (Anadenanthera peregrina var. falcata) é uma leguminosa arbórea economicamente importante (Lorenzi, 1992) que apresenta nódulos (Cordeiro \& Beltrati, 1989) e mi corrizas arbusculares (Thomazini, 1974) nas suas raízes. Para o crescimento e estabel ecimento de diversas espécies arbóreas, a dupla inoculação rizóbio/fungos micorrízicos parece ser um procedimento vantajoso, favorecendo, por exemplo, a produção de biomassa (Dela Cruz et al., 1988; Herrera et al., 1993). Entretanto, o benefício desses dois microssimbiontes para a planta pode depender da compatibilidade entre a estirpe do rizóbio e o fungo micorrízico inoculado, como observado em Anadenanthera peregrina (Gonçalves et al., 1995) e Dal bergia nigra (Scotti, 1997).

O objetivo deste trabalho foi avaliar o efeito da nodulação e da micorrização no crescimento inicial das plantas de A. peregrina var. fal cata em solo de cerrado autoclavado ou não autoclavado.

\section{MATE RIAL E MÉTODOS}

O experimento foi real izado em casa de vegetação do Instituto de Biociências da Universidade Estadual Paulista (UNESP), em Rio Claro (SP), no período de abril de 2000 a fevereiro de 2001 . O solo utilizado foi amostrado na reserva de Cerrado do município de Corumbataí (22015'S 47900'W, altitude de $810 \mathrm{~m}$ ), caracterizado em sua granulometria e anal isado quimicamente, segundo Raij (1981), antes e depois da autoclavagem feita a 157,5 Pa por $2 \mathrm{~h}$ (Quadro 1). Nenhuma correção ou adubação do solo foi realizada.

As sementes de Anadenanthera peregrina (L.) Speg. var. falcata (Benth.) Altschul (LeguminosaeMimosoi deae), obtidas junto ao Instituto Florestal (Secretaria do Meio Ambiente do estado de São Paulo), foram desinfestadas superficialmente com álcool $96 \%$ por $2 \mathrm{~min}$, seguido por um banho em hipoclorito de sódio a $2 \%$ por $5 \mathrm{~min}$, e abundantemente lavadas em água destilada esterilizada (Vincent, 1970). As sementes foram colocadas para germinar em placas de Petri com papel de filtro e água destilada esterilizada, sob luminosidade constante. As plântulas com três dias de idade foram transplantadas para sacos plásticos (de pol ietileno) de $6 \mathrm{~L}$, que continham amostras do solo de cerrado, os quais foram mantidos em casa de vegetação, sob condições naturais de fotoperíodo, com monitoração diária da umidade relativa e da temperatura.

O método empregado para a inoculação dos rizóbios nas plantas foi descrito por Gross et al. (2002). Para inoculação dos fungos micorrízicos 
Quadro 1. Características químicas e granulométrica de amostra do solo de cerrado não autoclavado (NA) e autoclavado (A)

\begin{tabular}{|c|c|c|}
\hline Característica & Não autoclavado & Autoclavado \\
\hline $\mathrm{pH} \mathrm{CaCl} 2$ & 3,9 & 3,8 \\
\hline M.O. $\left(\mathrm{g} \mathrm{dm}^{-3}\right)$ & 17 & 14 \\
\hline$P\left(\mathrm{mg} \mathrm{dm}^{-3}\right)$ & 2 & 2 \\
\hline $\mathrm{K}\left(\mathrm{mmol}_{\mathrm{c}} \mathrm{dm}^{-3}\right)$ & 0,4 & 0,6 \\
\hline $\mathrm{Ca}\left(\mathrm{mmol}_{\mathrm{c}} \mathrm{dm}^{-3}\right)$ & 1 & 1 \\
\hline $\mathrm{Mg}\left(\mathrm{mmol}_{\mathrm{c}} \mathrm{dm}^{-3}\right)$ & 1 & 1 \\
\hline $\mathrm{H}+\mathrm{Al}\left(\mathrm{mmol}_{\mathrm{c}} \mathrm{dm}^{-3}\right)$ & 31 & 28 \\
\hline Al $\left(\mathrm{mmol}_{\mathrm{c}} \mathrm{dm}^{-3}\right)$ & 7,3 & 6,9 \\
\hline $\mathrm{SB}\left(\mathrm{mmol}_{\mathrm{c}} \mathrm{dm}^{-3}\right)$ & 2,4 & 2,6 \\
\hline $\operatorname{CTC}\left(\mathrm{mmol}_{\mathrm{c} \mathrm{dm}}^{-3}\right)$ & 33,4 & 30,6 \\
\hline V (\%) & 7 & 8 \\
\hline$N(\%)$ & 0,075 & 0,100 \\
\hline$B\left(\mathrm{mg} \mathrm{dm}^{-3}\right)$ & 0,58 & 0,73 \\
\hline $\mathrm{Cu}\left(\mathrm{mg} \mathrm{dm}^{-3}\right)$ & 0,6 & 0,5 \\
\hline $\mathrm{Fe}\left(\mathrm{mg} \mathrm{dm}^{-3}\right)$ & 110 & 154 \\
\hline $\mathrm{Mn}\left(\mathrm{mg} \mathrm{dm}^{-3}\right)$ & 1,0 & 1,8 \\
\hline $\mathrm{Zn}\left(\mathrm{mg} \mathrm{dm}^{-3}\right)$ & 0,4 & 0,4 \\
\hline $\mathrm{S}\left(\mathrm{mg} \mathrm{dm}^{-3}\right)$ & 5 & 5 \\
\hline Areia grossa $\left(\mathrm{g} \mathrm{kg}^{-1}\right)$ & \multicolumn{2}{|c|}{560} \\
\hline Areia fina $\left(\mathrm{g} \mathrm{kg}^{-1}\right)$ & \multicolumn{2}{|c|}{370} \\
\hline Silte $\left(\mathrm{g} \mathrm{kg}^{-1}\right)$ & \multicolumn{2}{|c|}{10} \\
\hline Argila $\left(\mathrm{g} \mathrm{kg}^{-1}\right)$ & \multicolumn{2}{|c|}{60} \\
\hline
\end{tabular}

arbusculares (FMAs), foi empregado o método descrito por Strullu \& Romand (1986). Segmentos de raízes de milho colonizadas com Glomus spp. e Acaul ospora spp. coletadas no canteiro do J ardim Experimental do Departamento de Botânica da UNESP, Rio Claro, foram desinfestadas na sua superfície em etanol $95 \%$ e banhadas, duas vezes, em água destilada esterilizada. Após isto, foram tratadas com hipocl orito de cál cio a $6 \%$ por $2 \mathrm{~min}$, novamente lavadas com água destilada esterilizada e colocadas em uma solução antibiótica de sulfato de estreptomicina (200 $\left.\mathrm{mg} \mathrm{L}^{-1}\right)$ durante $15 \mathrm{~min}$. As raízes desinfestadas $(0,4 \mathrm{~g})$ foram colocadas junto às plântulas de angico-do-cerrado com oito dias de idade.

O experimento consistiu dos seguintes tratamentos, cada um com cinco repetições e duas col etas (quatro e 10 meses): sem inoculação dos microssimbiontes em solo autoclavado (A); sem inoculação dos microssimbiontes em solo não autoclavado (NA); com inoculação dos FMAs e rizóbios em sol o autoclavado $(A+F+R)$; inoculação com fungos em solo autoclavado $(A+F)$; inoculação com rizóbios em solo autoclavado $(A+R)$.

No quarto e décimo mês, as plantas foram coletadas e aval iadas quanto à massa seca das raízes, xilopódio e parte aérea. No décimo mês, foram analisados também os teores de N, P, K, Ca, Mg eS dessas três partes da planta, a percentagem de colonização das raízes e o número de nódulos por planta. Os teores de nutrientes na planta foram determinados, segundo Malavolta et al. (1989). Para determinar a percentagem de colonização micorrízica, as raízes foram clarificadas com $\mathrm{KOH}$ a $10 \%$ em banho-maria a 90 ㄷ e coradas com azul de tripan (Phillips \& Hayman, 1970). O tempo de clarificação foi prolongado em virtude da extensiva presença de compostos fenólicos nas raízes. Procedeu-se à avaliação da colonização com auxílio de ester eomicroscópio, empregando-se o método de interseção em placa quadriculada (Giovannetti \& Mosse, 1980).

Os resultados foram submetidos a análises de variância, e as médias foram comparadas pel o teste de Tukey a $5 \%$, utilizando o programa "SAS System for Windows-rel ease 6.11"(SAS, 1996). Os dados de percentagem de col onização radicular foram previamente submetidos à transformação $\operatorname{arc}$ sen $(x / 100)^{1 / 2}$.

\section{RESULTADOS E DISCUSSÃO}

Observou-se que, aos quatro meses, somente as plantas do tratamento solo A + R apresentaram menor acúmulo de biomassa total, graças aos menores valores de massa seca das raízes, xilopódio e parte aérea (Figura 1). Aos 10 meses de idade, as plantas do tratamento $A+F+R$ apresentaram biomassa total significativamente maior do que todos os outros tratamentos, conseqüência dos efeitos positivos da inoculação concomitante dos fungos micorrízicos e dos rizóbios no desenvolvimento do angico-do-cerrado.

Quando se analisou separadamente a produção de massa seca na raiz e na parte aérea, observou-se que as plantas do sol o não autod avado (tratamento NA) apresentaram os mai ores valores aos 10 meses (Figura $1 b$ ), porém não diferiram estatisticamente dos valores obtidos para as plantas do tratamento $A+F+R$. Esses resultados evidenciam que a alta taxa de col onização micorrízica e que o maior número de nódulos (Quadro 2), propiciados pelos fungos e rizóbios nativos do sol o de cerrado não autocl avado, influenciaram oacúmulo de matéria seca das plantas do tratamento NA. Esses resultados são, também, indício de um provável efeito sinergístico dos microssimbiontes nas plantas de angico-do-cerrado.

O xilopódio é um órgão presente em muitas espécies de plantas do cerrado e sua função parece estar relacionada com o armazenamento de reservas decarboidratos (Rizzini \& Heringer, 1961). As plantas do tratamento NA apresentaram valores menores para massa de matéria seca do xilopódio, graças, provavel mente, ao dreno de carboidratos desseórgão de armazenamento para os FMAs e rizóbios nativos, cujo número foi superior, o que podeser comprovado pelos valores apresentados para percentagem de mi corrização e número de nódul os (Quadro 2). 


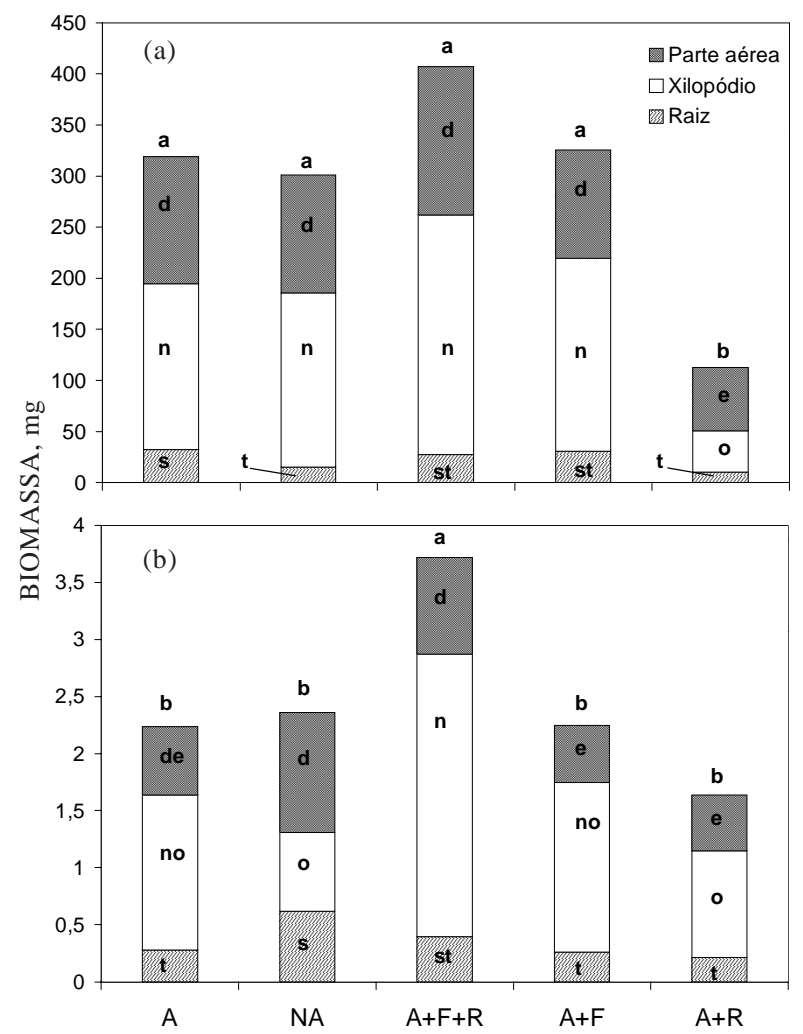

Figura 1. Biomassa total da raiz, xilopódio e parte aérea das plantas de angico-do-cerrado com quatro (a) e 10 meses (b). Letras diferentes (a, b, para biomassa total; d, e, para parte aérea; n, o, para xilopódio; s, t, para raiz) indicam diferenças significativas $(p<0,05)$ dentro de cada idade das plantas. $\mathbf{A}=$ plantas em solo autoclavado; $\mathbf{N A}=$ não autoclavado; $(\mathbf{A}+\mathbf{F}+\mathbf{R})$ = autoclavado e inoculadas com fungos micorrízicos e rizóbios; $(A+F)=$ autoclavado e inoculadas com fungo; $(A+R)=$ autoclavado e inoculadas com rizóbio.

Pode-se, ainda, observar (Quadro 2), que a nodulação foi significativamente maior nas plantas do tratamento $A+F+R$ do que nas do tratamento $A+R$, podendo o fósforo absorvido e translocado pelas micorrizas para a planta ter influenciado positivamente o estabel ecimento e a ocorrência de nódulos. De maneira geral, o número de nódulos nas plantas do presente experimento foi maior do que o das plantas de idade similar no seu ambiente natural, nas quais Cordeiro (1986) verificou valores de 13,2 nódulos por planta.

A taxa de colonização mi corrízica observada para as plantas do tratamento $A+F+R$ não diferiu estatisticamente daquela encontrada para as plantas do tratamento $A+F$ não atingindo valor muito abaixo de $11 \%$, relatado para a mesma espécie de planta com quatro meses por Siqueira et al. (1998). No entanto, a baixa taxa de col onização mi corrízica encontrada nas plantas inoculadas nos tratamentos
Quadro 2. Percentagem de colonização mi corrízica e número de nódulos das raízes das plantas em solo autoclavado (A), não autoclavado (NA), autoclavado $e$ inoculadas com fungos micorrízicos e rizóbios ( $A+F+R)$, autoclavado e inoculadas com fungo $(A+F)$, autoclavado $e$ inoculadas com rizóbio (A + R)

\section{Tratamento \% de colonização(1) № de nódulo(1)}

\begin{tabular}{lcc}
\hline$A$ & 0 & 0 \\
$N A$ & $78 a$ & $57 a$ \\
$A+F+R$ & $9 b$ & $48 a$ \\
$A+F$ & $4 b$ & 0 \\
$A+R$ & 0 & $19 b$
\end{tabular}

(1) Médias seguidas de letras diferentes, na coluna, diferem estatisticamente entre si pelo teste de Tukey a $5 \%$.

com solo autoclavado pode ter sido devida a pouca eficácia da inoculação aplicada ou mesmo a certa incompati bilidade entre os FMAs provindos da raiz demilho e do angico-do-cerrado. Essa baixa taxa de colonização micorrízica nas plantas inoculadas contrasta com a alta taxa observada nas plantas do tratamento NA.

Como as plantas deste tratamento estavam micorrizadas por FMAs nativos, foi interessante realizar levantamento dessas espécies do solo de cerrado não autoclavado utilizado no presente experimento. Foram identificados esporos das espécies Glomus mi croaggregatum, Glomus etunicatum, Glomus sp., Enthrophospora sp., Gigaspora sp. Duas espécies de Acaulospora. estavam presentes nesse solo. A ocorrência de 24 espécies de FMAs foi relatada por Bononi \& Trufem (1983) quando realizaram um extensivo levantamento em solos de cerrado da reserva biológica de Moji-Guaçu. A ausência de colonização fúngica e de nódulos nas plantas não inoculadas e cultivadas em sol o autoclavado indica que não houve contaminação e que o processo de autoclavagem foi eficiente na eliminação de propágulos micorrízicos e das populações de rizóbios do solo.

Foram observados efeitos positivos da inoculação dos rizóbios eFM As nos teores de nutrientes da parte aérea e xilopódio, porém pouco expressivos (Quadro 3). A influência dos rizóbios com relação ao aumento no teor de $\mathrm{N}$ foi notada noxilopódio das plantas do tratamento $A+R$, tendo sido observados maiores valores para esse nutriente na sua parte aérea enas suas raízes. O pequeno desenvol vimento das plantas desse tratamento (Figura 1b) possivelmente influenciou a concentração de $\mathrm{N}$ observada. Entretanto, esses valores foram bastante próximos aos das plantas do tratamento com solo autoclavado, indicativo da baixa eficiência no processo de fixação biológica do $\mathrm{N}$ por parte dos isolados de rizóbio. 
Analisando a influência da inoculação dos fungos micorrízicos nas plantas, verificou-se que os teores de $\mathrm{P}$ não diferiram significativamente tanto para parteaérea quanto para oxilopódio e os val ores para raízes não diferiram (Quadro 3) entre os tratamentos, considerando a baixa taxa de colonização das raízes (Quadro 2) e, ou, que as espécies de FMAs que col onizaram as raízes foram pouco eficientes na solubilização e absorção de P.

Observou-se, entretanto, um aumento significativo no teor de $\mathrm{P}$ na parte aérea exilopódio das plantas do tratamento NA não inoculadas. I sso pode ser explicado pela extensiva presença de micorrizas (78 \% de col onização das raízes para essas plantas), as quais foram formadas pelos FMAs nativos presentes no solo de cerrado não autoclavado. O maior teor de $\mathrm{P}$ para as plantas deste tratamento poderia acarretar um benefício nutricional geral, o que explicaria a maior absorção e as conseqüentes diferenças significativas encontradas para teor $\mathrm{K}$ na parte aérea e teores $\mathrm{Ca}$ e $\mathrm{S}$ no xilopódio dessas plantas.

Recomenda-se certo cuidado ao tentar explicar essas diferenças de teores denutrientes encontradas, em virtude da variação intra-específica na concentração de alguns elementos que é quase sempre igual ou mesmo superior à variação interespecífica (Grimshaw \& Allen, 1987; Ohlson, 1988; Thompson et al., 1997). Devem-se levar em conta também os sinergismos eantagonismos entre os nutrientes (Marschner, 1986), bem como devemse considerar as correlações entre diferentes nutrientes que podem ser encontradas em diferentes espécies de plantas. Assim, por exemplo, Alonso \& Herrera (2001), estudando populações de Prunus mahaleb, encontraram uma consistente correlação positiva entre Ca e Mg, porém não a encontraram entre $\mathrm{N}$ e $\mathrm{P}$, el ementos que geral mente apresentam correlação positiva (Thompson et al., 1997).

As plantas respondem diferentemente à deficiência ou baixa disponibilidade de nutrientes do ambiente e apresentam diferentes necessi dades fisiológicas que causam diversidades no seu metabolismo e constituição (Chapin, 1980). A pesar dessa variaçãona concentração de nutrientes do solo, as plantas de ambientes adversos apresentam valores mais consistentes na concentração desses elementos nos tecidos, sendotambém uma estratégia conservativa no uso desses recursos (Valladares et al., 2000). E ste comportamento parece ocorrer com angico-do-cerrado, como pode ser evidenciado pelos resultados obtidos no presente experimento, os quais concordam com os obtidos por Carneiro et al. (1996) e Siqueira et al. (1998) em que os valores

Quadro 3. Teores de nutriente na parte aérea, xilopódio e raiz das plantas em solo autoclavado (A), não autoclavado (NA), autoclavado e inoculadas com fungos micorrízicos e rizóbios $(A+F+R)$, autoclavado e inoculadas com fungos micorrízicos $(A+F)$, autoclavado e inoculadas com rizóbio $(A+R)$. Médias de cinco repetições para a parte aérea e xilopódio. Para as raízes médias de três repetições para plantas dos tratamentos NA eA $+F+R$, médias de duas repetições para os tratamentos $A$ e A +F, e valor único obtido para o tratamento $A+R$

\begin{tabular}{|c|c|c|c|c|c|c|c|}
\hline & Tratamento & $\mathbf{N}$ & $\mathbf{P}$ & $\mathbf{K}$ & $\mathrm{Ca}$ & $\mathbf{M g}$ & $\mathbf{S}$ \\
\hline & & \multicolumn{6}{|c|}{$-\mathrm{mg} \mathrm{kg}^{-1}$} \\
\hline Parte aérea & $\begin{array}{l}A \\
N A \\
A+F+R \\
A+F \\
A+R \\
C . V .(\%)\end{array}$ & $\begin{array}{l}20,0 a \\
17,7 a \\
16,8 a \\
18,5 a \\
21,1 a \\
13,08\end{array}$ & $\begin{array}{c}0,70 \mathrm{~b} \\
1,48 \mathrm{a} \\
0,74 \mathrm{~b} \\
0,80 \mathrm{~b} \\
0,62 \mathrm{~b} \\
19,19\end{array}$ & $\begin{array}{c}9,94 a \\
10,30 a \\
8,68 a b \\
8,74 a b \\
6,94 b \\
10,66\end{array}$ & $\begin{array}{l}14,0 a \\
12,3 a \\
16,5 a \\
13,8 a \\
13,4 a \\
20,73\end{array}$ & $\begin{array}{c}1,06 a \\
1,60 a \\
1,26 a \\
0,98 a \\
1,08 a \\
27,65\end{array}$ & $\begin{array}{c}1,06 a \\
1,82 a \\
1,12 a \\
1,86 a \\
1,30 a \\
28,63\end{array}$ \\
\hline Xilopódio & $\begin{array}{l}A \\
N A \\
A+F+R \\
A+F \\
A+R \\
C . V .(\%)\end{array}$ & $\begin{array}{c}18,3 \mathrm{ab} \\
9,5 \mathrm{c} \\
15,5 \mathrm{~b} \\
17,6 \mathrm{~b} \\
21,7 \mathrm{a} \\
16,43\end{array}$ & $\begin{array}{c}0,34 b \\
2,70 a \\
0,34 b \\
0,32 b \\
0,32 b \\
12,21\end{array}$ & $\begin{array}{r}7,66 a \\
6,20 a \\
6,64 a \\
6,50 a \\
6,36 a \\
12,98\end{array}$ & $\begin{array}{c}4,60 a b \\
5,30 a \\
3,48 b \\
3,94 a b \\
4,32 a b \\
18,15\end{array}$ & $\begin{array}{c}1,22 a \\
1,93 a \\
0,92 a \\
1,14 a \\
1,14 a \\
17,20\end{array}$ & $\begin{array}{c}1,88 \mathrm{~b} \\
2,76 \mathrm{a} \\
1,00 \mathrm{c} \\
1,42 \mathrm{bc} \\
1,60 \mathrm{~b} \\
18,16\end{array}$ \\
\hline Raiz(2) & $\begin{array}{l}A \\
N A \\
A+F+R \\
A+F \\
A+R\end{array}$ & $\begin{array}{l}11,5 \\
10,5 \\
10,5 \\
13,0 \\
14,0\end{array}$ & $\begin{array}{l}0,65 \\
1,00 \\
0,57 \\
0,55 \\
0,60\end{array}$ & $\begin{array}{r}9,15 \\
6,80 \\
7,17 \\
10,00 \\
6,80\end{array}$ & $\begin{array}{l}4,40 \\
4,80 \\
5,07 \\
6,60 \\
4,60\end{array}$ & $\begin{array}{l}2,85 \\
1,90 \\
3,00 \\
3,15 \\
2,20\end{array}$ & $\begin{array}{l}2,60 \\
2,53 \\
2,07 \\
3,45 \\
2,40\end{array}$ \\
\hline
\end{tabular}

(1) Médias seguidas de letras diferentes na vertical para cada parte da planta (xilopódio e parte aérea) diferem estatisticamente entre si pelo teste de Tukey a $5 \%$. ${ }^{(2)}$ Considerando a falta de repetições para os teores de nutrientes das raízes do tratamento A + $\mathrm{R}$, não foram realizadas comparações por meio de testes estatísticos. 
apresentados para concentração de P, K, Mg, Ca eS na parte aérea não diferem significativamente entre os tratamentos-controle, inoculação com FMAs, adição de superfosfato simples e aplicação conjunta de FMAs e superfosfato simples.

As plantas de angico-do-cerrado do presente experimento não apresentaram sintoma aparente de deficiência nutricional, apesar da baixa concentração dos nutrientes no solo utilizado, isso por estarem adaptadas às condições edáficas, em geral álicas, do cerrado. Em populações de Prunus mahaleb, a variação ambiental na disponibilidade de nutrientes favorece a plasticidade ao invés da especialização genética, e a habilidade das plantas se desenvolverem tanto em locais de alta como de baixa concentração em nutrientes parece ser um aspecto importante na adaptação do indivíduo ao ambiente (Alonso \& Herrera, 2001). Em angico-docerrado, a plasticidade no crescimento e desenvolvimento dessa espécie, assim como sua boa resposta à adubação mineral, pode ser comprovada, comparando a produção de biomassa das plantas do tratamento NA nesse experimento $(2,36 \mathrm{~g}$ aos 10 meses) com a das plantas da mesma idade que receberam adubação completa em substrato deareia evermiculita do experimento realizado por Gross et al. (2002), que tiveram uma produção de biomassa de aproximadamente $15 \mathrm{~g}$.

\section{CONCLUSÕES}

1. A inoculação concomitante deFMAs e rizóbios incrementou a produção de biomassa nas plantas de angico-do-cerrado.

2. Plantas cultivadas em solo de cerrado não autoclavado apresentaram al ta taxa de col onização fúngi ca nas suas raízes, influenciando positivamente os teores de $\mathrm{P}$ dessas plantas.

3. As plantas inoculadas apenas com rizóbio, apesar deseu pequeno desenvolvimento, apresentaram maior teor de $\mathrm{N}$ no xilopódio.

4. Angi co-do-cerrado mostrou grande plasticidade com relação ao crescimento em substratos com diferentes disponibilidades de nutrientes, o que pode ser um aspecto importante na sua adaptação ao ambiente.

\section{AGRADE CIMENTOS}

Os autores agradecem à Fundação de Amparo à Pesquisa do estado de São Paulo, pela concessão de bolsa ao primeiro autor, eà Profa. Dra. Sandra F.B. Trufem, da Seção de Micologia do Instituto de Botânica, pelo auxílio na identificação dos fungos micorrízicos arbusculares.

\section{LITE RATURA CITADA}

ALLEN, O.N. \& ALLEN, E.K. The leguminosae. A source book of characteristics, uses and nodulation. Madison, The University of Wiscosin Press, 1981. 812p.

ALONSO, C. \& HERRERA, C.M. Patterns made of patterns: variation and covariation of leaf nutrient concentrations within and between populations of Prunus mahaleb. New Phytol., 150:629-640, 2001.

BONONI V.L.R. \& TRUFEM, S.F.B. Endomicorrizas vesículoarbusculares do cerrado da reserva biológica de Moji-Guaçu, SP, Brasil. Rickia, 10:55-84, 1983.

CARNEIRO, M.A.C.; SIQUEIRA, J .O.; DAVIDE, A.C.; GOMES, L.J .; CURI, N. \& VALE, F.R. Fungo micorrízico e superfosfato no crescimento de espécies arbóreas tropicais. Sci. Fores., 50:21-36, 1996.

CHAPIN, F.S. The mineral nutrition of wild plants. Ann. Rev. Ecol. Sys., 11:233-260, 1980.

CORDEIRO, L. Caracterização de nódulos em leguminosas de cerrado. In: REUNIÃO LATINO-AMERICANA SOBRE RHIZOBIUM, 12., Campinas, 1986. Anais. Campinas, Instituto Agronômico, 1986. p.191-197.

CORDEIRO, L. \& BELTRATI, C.M. Estrutura e desenvol vimento de nódul os radiculares de Anadenanthera falcata Speg., R. Bras. Bot., 12:61-70, 1989.

DELA CRUZ, R.E.; MANALO, M.Q.; AGGANGAN, N.S. \& TAMBALO, J.D. Growth of three legume trees inoculated with V.A. mycorrhizal fungi and Rhizobium. Plant Soil, 108:111-115, 1988.

GIOVANNETTI, M. \& MOSSE, B. An evaluation of techniques for measuring vesicular-arbuscular mycorrhizal infection in roots. New Phytol., 84:482-500, 1980.

GONÇALVES, L.M.B.; MARQUES, M.S.; SILVA, P.F .; SCOTTI, M.R.M.M.L; VALLE, M.T.S. \& LEOS-FILHO, J.P. Efeito da dupla inoculação (Rhizobium/fungos micorrízicos) no crescimento de Anadenanthera peregrina em diferentes tipos de solo. In: CONGRESSO BRASILEIRO DE CIÊNCIAS DO SOLO, 25., Viçosa, 1995. Anais. Viçosa, Sociedade Brasileira de Ciências do Solo, 1995. p.534-535.

GRIMSHAW, H.M. \& ALLEN, S.E. Aspects of the mineral nutrition of somenative Britsh plants - inter-sitevariation. Vegetatio, 70:157-169, 1987.

GROSS, E.; CORDEIRO, L. \& CAETANO, F.H. Nodule ultrastructure and initial growth of Anadenanthera peregrina (L.) Speg. var. falcata (Benth.) Altschul plants infected with rhizobia. Ann. Bot., 90:175-183, 2002.

HARLEY,J .L. \& SMITH, S.E. Mycorrhizal symbiosis. New York, Academic Press, 1983. 483p.

HERRERA, M.A.; SALAMANCA, C.P. \& BAREA, J.M. Inoculation of woody legumes with selected arbuscular mycorrhizal fungi and rhizobia to recover desertified mediterranean ecosystems. Appl. Environ. Microbiol., 53:129-133, 1993. 
LORENZI, H. Árvores brasileiras: manual de identificação e cultivo de plantas arbóreas nativas do Brasil. Nova Odessa, Plantarum, 1992. 352p.

MALAVOLTA, E.; VITTI, G.C. \& OLIVEIRA, S.A. Avaliação do estado nutricional das plantas. Piracicaba, Associação Brasileira para Pesquisa da Potassa e do Fosfato, 1989. 201p.

MARSCHNER, H. Mineral nutrition of higher plants. London, Academic Press, 1986. 889p.

OHLSON, M. Variation in tissue element concentration in mire plants over a range of sites. Hol oart. Ecol., 11:267-279, 1988.

PHILLIPS, J.M. \& HAYMAN, D.S. Improved procedures for clearing roots and staining parasitic and vesiculararbuscular mycorrhizal fungi for rapid assesment of infection. Trans. Br. Mycol. Soc., 55:158-161, 1970.

RAIJ, B. van. Avaliação da fertilidade do solo. Piracicaba, Associação Brasileira para Pesquisa da Potassa e do Fosfato, 1981. 142p.

RIZZINI, C.T. \& HERINGER, E.P. Underground organs of plants from some Brazilian savannas, with special reference to the xylopodium. Phyton, 17:105-24, 1961.

SAS INSTITUTE INCORPORATION. The SAS-System for Windows release 6.11 (software). Cary, 1996.
SCOTTI, M.R.M.M.L. Fixação biológica do nitrogênio por espécies arbóreas. In: VARGAS, M.A.T. \& HUNGRIA, M., eds. Biologia dos solos dos cerrados. Planaltina, EMBRAPACPAC, 1997. p.153-186.

SIQUEIRA, J.O.; CARNEIRO, M.A.C.; CURI, N.; ROSADO, S.C.S. \& DAVIDE, A.C.. Mycorrhizal colonization and mycotrophic growth of native woody species as related to successional groups in Southeastern Brazil. For. Ecol. Manag., 107:241-252, 1998.

STRULLU, D.G. \& ROMAND, C. Méthode d'obtention d'endomycorhizes à vésicules et arbuscules en conditions axéniques. C. R. Acad. Sci., 3:303:245-250, 1986.

THOMAZINI, L.I. Mycorrhiza in plants of the "Cerrado". Plant Soil, 41:707-711, 1974

THOMPSON, K.; PARKINSON, J .A.; BAND, S.R. \& SPENCER, R.E. A comparative study of leaf nutrient concentrations in a regional herbaceous flora. New Phytol., 136:679-689, 1997.

VALLADARES, F.; MARTÍNEZ-FERRI, E.; BALAGUER, L.; PÉREZ-CORONA, E. \& MANRIQUE, E. Mediterranean evergreen oaks: a conservative resourse-use strategy? N ew Phytol., 148:79-91, 2000.

VINCENT, J .M. A Manual for the practical study of root nodule bacteria. Oxford, Blackwell Scientific Publication, 1970. $164 p$. 